\title{
Meeting the mental and physical healthcare needs of carers
}

\author{
Irene Cormac \& Peter Tihanyi
}

Abstract The health of family carers may affect not only their own lives but also the lives of the people for whom they provide care. This article describes how the caring role can affect the health and well-being of a carer of a person who has a mental or physical disorder. Suggestions are made about how to recognise and ameliorate some of the detrimental effects of the caring role on the carer's own health.

Carers are non-professionals who provide help and support to people who are sick, infirm or disabled (Singleton et al, 2002). The role of the carer is especially important when the person who receives care (the care recipient) is unable to live independently without the carer's help. A young carer is a child or young person under the age of 18, carrying out significant caring tasks and assuming a level of responsibility for another person that normally would be undertaken by an adult.

Underpinning the caring role may be life-long love and friendship, together with an acceptance of the duty to provide care. Carers can derive satisfaction and a sense of well-being from their caring role, receive love and affection from the care recipient, gain a sense of achievement from developing personal attributes of patience and tolerance, and gain satisfaction from meeting cultural or religious expectations (Cassell et al, 2003).

Caring responsibilities may arise at any time in life. Carers may have to adapt and change their daily routine for work and social life, perhaps incurring personal and financial costs. They may become isolated from other members of their family, friends and work colleagues. In an ageing population, family members are expected to undertake complex care tasks, often at great cost to their own well-being and health (Schulz \& Matire, 2004).

Communication with others may become frustrating, especially when a carer perceives comments and advice to be overly optimistic or to lack a realistic understanding of the situation. Carers may have too much or too little information about the condition of the care recipient. They may take on sole responsibility for caring, to the exclusion of their other roles, leading to lasting effects on relationships with family and friends.

The role of carer can be demanding and difficult, irrespective of whether the care recipient has a mental disorder, learning disability or a physical disability, either separately or combined. This article aims to raise awareness of carers' health needs and suggests ways to meet them.

\section{Characteristics of carers}

In the UK 2001 census (Office for National Statistics, 2003), it was found that 5.8 million carers provide care for people with physical and mental disorders, mostly in their own homes (Box 1). Of these, 1.25 million provide care for over $50 \mathrm{~h}$ a week. There are 175000 young carers aged under 18 . The peak age for carers is between the fifth and seventh decades (Travers, 1996).

An estimated $40-50 \%$ of all carers provide care for another family member or friend with a mental health problem. Of these, about $11 \%$ care for people with dementia, $14 \%$ for people with learning disabilities or an autistic-spectrum disorder, $7 \%$ care for people with psychosis, schizophrenia or depression, and $8 \%$ for those with both mental and physical illness or disabilities (Keeley \& Clarke, 2002).

On average, carers provide care for 4 years, with $40 \%$ providing care for less than a year and $25 \%$ for more than 10 years. Although a carer may relinquish

\footnotetext{
Irene Cormac practises as a consultant forensic psychiatrist with a special interest in physical healthcare at Rampton Hospital (Retford, Nottinghamshire DN22 OPD, UK. Email: irene.cormac@nottshc.nhs.uk). At Rampton Hospital, she has been involved in the development of a healthy lifestyle programme to improve the physical health of long-stay psychiatric patients. Peter Tihanyi is the Head of Policy, Conferences and Carers' Funds for the Princess Royal Trust for Carers, the largest national charity providing services for carers in the UK. He has worked with carers since 1994, after working in day care services with elderly people and adults with mental health difficulties and physical disabilities. The authors were members of the campaign committee for 'Partners in Care', a joint campaign for carers run by the Royal College of Psychiatrists and the Princess Royal Trust for Carers.
} 


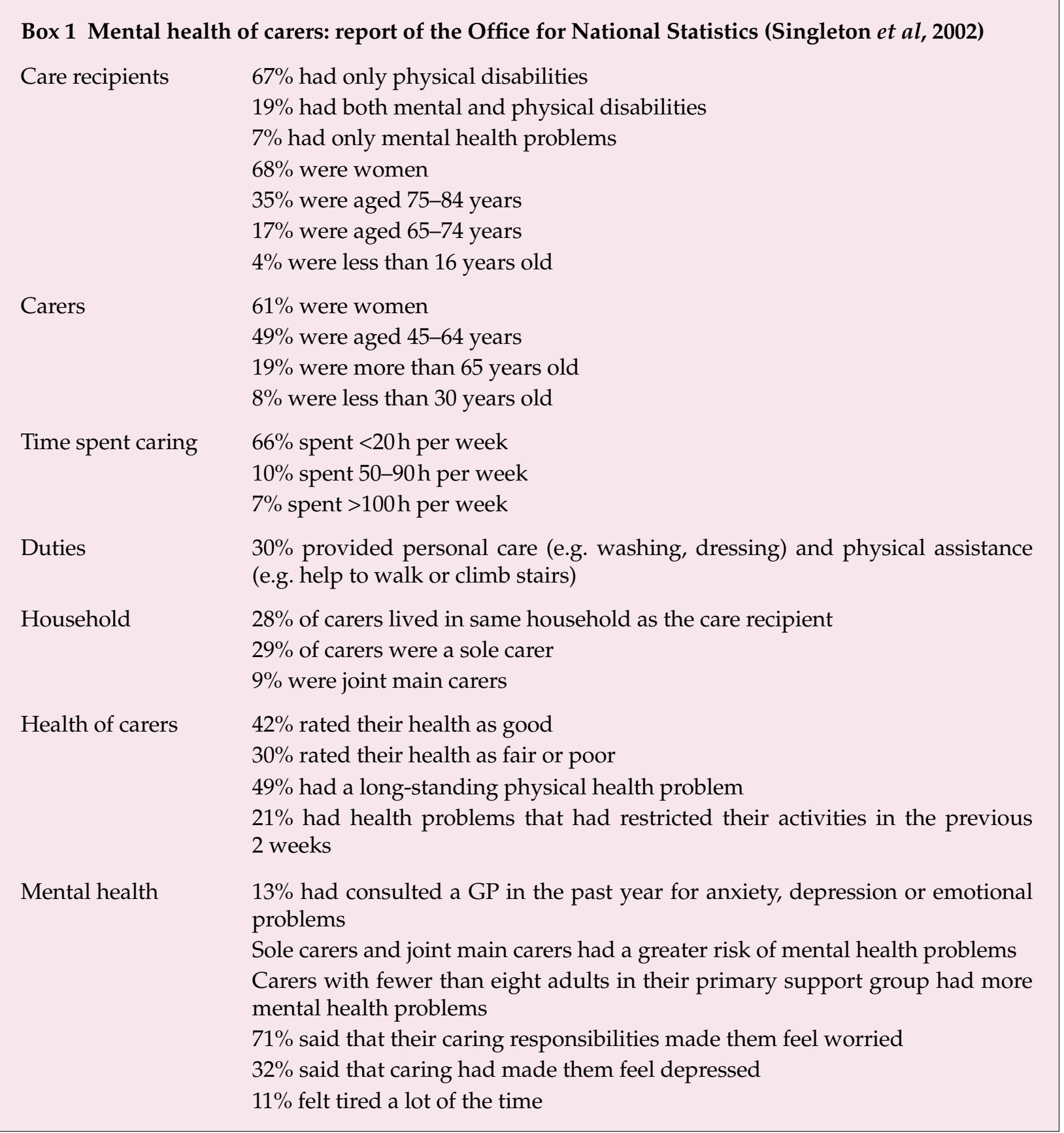

day-to-day responsibilities for a person living in an institution, they may continue to provide long-term emotional and financial support.

A carer's job description would be unlikely to attract many applicants (Box 2).

\section{Impact of caring on carers' health} Views of carers about their health

A survey of over 1000 carers in contact with carers' organisations found that just less than $50 \%$ believed that their health was adversely affected by their caring role (Cheffings, 2003). Mental health problems included stress and tension (38\%), anxiety (27\%) and depression (28\%). Physical health problems included back injury $(20 \%)$ and hypertension $(10 \%)$. Back injury was associated with caring for individuals with physical disabilities. Similar figures were found in a survey by Carers UK (2002), in which the most frequently experienced negative emotions in carers were: feelings of being mentally and emotionally drained $(70 \%)$, physically drained $(61 \%)$, frustration $(61 \%)$, sadness for the care recipient $(56 \%)$, anger $(41 \%)$, loneliness $(46 \%)$, guilt $(38 \%)$ and disturbed sleep $(57 \%)$. 


\section{Box 2 Job description for a carer}

Essential personal attributes

Patience, tolerance, endurance, perseverance, inner strength, sense of humour and ability to communicate at all levels

Ideal candidates will have skills and experience in: Nursing, counselling, physiotherapy, chiropody, dietetics, cooking, housekeeping, hairdressing, accountancy, gardening, DIY and driving

\section{Hours}

You must be prepared to be on-call 24 hours a day, 7 days a week, 52 weeks a year

Holidays and services

Only if you are very lucky and your local area provides respite care. No Bank Holidays allowed; instead you may have to work extra without pay

\section{Salary}

Probably nothing, but may be up to $£ 2400$ a year, provided that strict conditions are fulfilled and a long and complicated form is completed

Other terms and conditions

No sick pay or time off and no union representation

Application

No need to apply, as you will become a carer when a member of your family or a friend needs your help

\section{Research on the mental health of carers}

A New Zealand study found that carers and noncarers did not differ on measures of depression or subjective measurements of health (Knight et al, 1998). In the UK, Livingston et al (1996) found that being a carer of an older person was not by itself a risk factor for a psychiatric illness or psychological symptoms. They also noted that there was also an increase in psychiatric morbidity in carers of individuals with psychiatric disorders compared with carers of people with physical disoders, which was partly attributed to a lack of a confiding relationship.

In a survey by Singleton et al (2002), almost twothirds of carers had more than eight family members or friends to whom they felt close and these carers were less likely to have mental health problems $(13 \%)$ than carers in smaller social groups, of whom $26 \%$ reported mental health problems.
In a study by Knight et al (1998) higher 'burden of care' scores were predicted by co-residence, low satisfaction with social support and poorer health ratings on the part of the carers, but not by the quality of the relationship between the person cared for and the carer. Carers found employment outside their home to be beneficial to their general well-being.

Carers who are more vulnerable to health problems are women, elderly or very young people, those with pre-existing poor physical health, carers with arduous duties and those with few social contacts or support. Carers may attribute symptoms of an illness to their work as a carer and fail to recognise the onset of an illness.

\section{Physical health of carers}

The physical health of carers has been shown to be adversely affected, with increased rates of hypertension (King et al, 1994), lower immune response (Kiecolt-Glaser et al, 1991), altered response to influenza vaccination (Kiecolt-Glaser et al, 1996) and slowing of response to wound healing (KiecoltGlaser et al, 1995).

In the USA, Sunmin Lee et al (2003) found that caring for $9 \mathrm{~h}$ per week was associated with twice the risk of coronary heart disease in female carers. Schulz \& Beach (1999) reported that elderly carers living with the care recipient, who also experience psychological strain associated with being a carer, are more likely to die within 4 years than elderly non-carers (relative risk 1.63, 95\% CI 1.00-2.65). They recommend that older married couples should be evaluated as a unit and that consideration should be given to providing institutional care when necessary. Other studies found that the presence of depressive symptoms was not a significant predictor of poor physical health in carers (O'Rourke et al, 2003) but led to increased use of services (Bookwala et al, 2004).

\section{Emotional well-being of carers}

At any stage of the caring role, carers can feel trapped, resentful, angry or upset and excluded from society. During the early stages of a care recipient's illness, carers often grieve over the loss of the 'person they knew' or 'what might have been' and the loss of mutual support and reciprocity in their relationship with the care recipient.

Carers cope better if they have long-standing love and affection for the care recipient at the onset of caring. Carers who have the ability to accept their situation and solve problems are better able to adjust to their change in role and level of responsibility. 


\section{Characteristics of care recipient}

The nature of the care recipient's disorder or disability can make the carer feel stigmatised. In an Australian study of older carers, one-third were unable to leave the care recipient alone and 20\% of all carers were too embarrassed to ask for help (O'Connell et al, 2003).

\section{Care recipients with mental disorders}

The effect of a mental illness or disorder on families has been described by Perring et al (1992). Families coping with a relative with a mental illness have most difficulty dealing with behaviour such as social withdrawal, restlessness and pacing, frequent demands, nocturnal disturbances, bizarre or unusual behaviour and suicide attempts. It is difficult for carers to cope with fluctuations in the course of a mental illness or disorder. There may be increased complexity in the interactions between care recipients and their carers, leading to marital discord and family conflict. Younger children are especially vulnerable to family disturbances and the effects of these on carer and care recipient. Some children become carers themselves, experiencing disruption to their lives and education.

Carers tend to worry most about the risk of suicide if they leave the care recipient alone and what will happen to their dependent care recipient when they are no longer able to provide care.

About $65 \%$ of carers of individuals with mental disorders report that they receive no support whatsoever (Keeley \& Clarke, 2002). The factors affecting whether a carer will seek help include the manifestations of the illness or disorder, availability of information, how long it will take to obtain treatment and perceived standards of mental health services. If carers experience a high burden of care, this can adversely affect the care recipient's mental health, through poor adherence to medication regimens (Perlick et al, 2004).

The age of the care recipient may affect a carer's reaction to the care role. In a study by Livingston et al (1996), carers of older people with mental disorders were found to be more likely to be depressed $(47 \%)$, particularly women caring for someone with dementia. A meta-analysis of 84 studies of the health of carers of older people found that, compared with non-carers, carers had higher levels of stress and depression and lower levels of subjective wellbeing, physical health and self-efficacy, especially those caring for a relative with dementia (Pinquart \& Sorensen, 2004).

In male carers of spouses with dementia, physical health symptoms were increased by one-third during the care period, compared with the periods before and after care provision (Shanks-McElroy \& Strobino, 2001). After care provision ends, the physical health of former carers of people with dementia has been shown to improve and they visit the doctor more frequently to attend to their own physical health needs (Grasel, 2002).

\section{Care recipients with physical disorders}

The caring role can be especially demanding when the care recipient has a physical disorder with a high burden of care or a reduced life expectancy, for example following a cerebrovascular accident or during the course of an illness due to cancer.

Research has shown that families of patients receiving palliative care are often profoundly affected psychologically by a care recipient's illness, with feelings of shame, guilt and regret, thus becoming 'hidden patients' themselves (Kristjanson \& Aoun, 2004). Cancer patients have multifaceted needs. So physicians, oncologists and other healthcare professionals such as psychiatrists should be aware of the demands made on carers of patients with cancer, especially elderly carers (Kurtz et al, 2004). It is advisable to offer carers a periodic assessment of their needs and concerns, together with a review of the patient's trajectory of illness, to ensure that carers are able to continue to provide care.

During the course of a terminal illness, carers may reflect on their own personal values and change their perspectives on what is important in life. The process of grieving may begin long before the care recipient's death and may compound a carer's difficulties, especially if they become depressed or anxious, or develop physical symptoms such as insomnia or poor appetite. Psychiatrists should bear in mind that grief might occur in anticipation and take this into consideration when planning psychiatric treatment for a carer.

Carers of victims of cerebrovascular accidents have been shown to be more at risk of burnout if the care recipient has severe cognitive, behavioural and emotional changes (van den Heuvel et al, 2001). Depression in the carers of stroke survivors is also more likely if carers have lower life satisfaction and lower physical functioning and lack tangible social support (Grant et al, 2000). Improving a carer's skills during rehabilitation of in-patients following strokes reduces the economic cost of care and improves carers' quality of life (Patel et al, 2004).

\section{Burden of care}

There are many practical issues that may distress carers (Box 3). A survey by the Princess Royal Trust for Carers (Cheffings, 2003) showed that the most 


\section{Box 3 Practical issues that can distress carers}

The care recipient's behaviour

- Social withdrawal

- Restlessness

- Pacing

- Bizarre behaviour

- Neglect of personal care and hygiene

- Awake at night and asleep all day

Care duties

- The frequent demands made

- Incontinence of urine, faeces or both

- Lack of laundry facilities

- Insufficient supply of linen/ bedding

- Attendance at medical out-patient appointments

- Domestic chores, gardening, providing transport and preparing meals

The carer's fears and worries

- Self-harm or suicide by the care recipient

- Death of care recipient

- Change of role in the relationship between carer and care recipient

- Loss of a confiding relationship

- Loss of a sexual relationship

- Deterioration in carer's own health

- Being excluded from information-sharing

stress and anxiety was caused by being woken at night and by verbal and or physical abuse. Constant watchfulness affects the quality of sleep and carers who are frequently disturbed at night will eventually become light sleepers (Cassells et al, 2003).

Whatever the nature of the disorder or the age of the care recipient, incontinence can cause social and practical difficulties. A carer may feel embarrassed or be unable to provide personal care. It is recommended that carers are provided at an early stage with advice and support from a specialist nurse on the management of incontinence. The combination of faecal and urinary incontinence often leads the carer to seek institutional care for the care recipient (Cassells et al, 2003).

In couples, deterioration in the care recipient's health can end their sexual relationship with the carer. The carer may be unable to confide in anyone, yet miss this aspect of life. Although healthcare professionals have a role in assisting patients with sex-related problems, many professionals continue to avoid the topic of sexual relationships and sexual health (Evans, 2000). Carers who wish to find a partner say they feel constrained by their caring role, fearing that it will be a barrier to a new relationship.

\section{Social and cultural factors}

It is important to understand how social and cultural beliefs can affect a carer's role, attitudes and readiness to accept help from professionals. Reporting on a study conducted in Hong Kong, Wong (2000) describes the cultural issues experienced by carers who hold traditional Chinese values and beliefs that affect their family expectations and obligations. These include the 'Confucian work ethic', the tendency for external attribution of blame and the need to deal with these issues by 'facesaving'. Careful consideration should be given to understanding the expectations of people from other areas and cultures.

Some carers enjoy and value recreation and social activities away from their care recipients. Others derive comfort from the support of people from their religious or social group. In a study in the USA (LeBlanc et al, 2004), religious belief was found to be more common in female carers and those from ethnic minority groups and was mostly unrelated to carers' stress.

\section{Relationship between carers, professionals and patients}

Carers should be seen by professionals as partners in promoting the care of service users (Hervey \& Ramsay, 2004). However, carers do not always want to be recognised as such or to receive help from professionals, although this attitude can alter when the health of the care recipient deteriorates or the carer's circumstances change. Most healthcare professionals involved in clinical care meet carers, either as their patients or as their patients' relatives or friends. Yet often carers' needs are poorly recognised by professionals and by care recipients (Kersten et $a l, 2001)$. Carers can feel undervalued by healthcare professionals and tend to rely on friends and family for support (Pinfold \& Corry, 2003). Many carers want to be included by healthcare professionals and to receive information about the care recipient's condition and treatment. However, the care recipient may want the carer to be excluded from contact with health professionals.

Carers realise that information is available but is not being provided to them. They are aware that professionals must maintain their patients' confidentiality, but perceive this to be frustrating and unhelpful. Feelings of anger and resentment about the illness or disorder can focus on issues of confidentiality. Similarly, a carer may wish to confide in the clinical team, without the patient's knowledge, and want the information given to be confidential. 
Information on patient confidentiality is available from the General Medical Council (2004) and the Royal College of Psychiatrists (2006). The College has also published a booklet specifically addressing issues of confidentiality involving carers of people with mental illnesses (Royal College of Psychiatrists, 2004). This contains useful advice, including negotiating with the patient to share less sensitive information and the provision of general information on, for example, the side-effects of medication and where to find help in a crisis. The information needed by a carer will vary with the type and stage of the patient's illness. Carers often find that they relate to one member of the multiprofessional team better than others.

\section{Services for carers}

\section{Government policy in England and Wales}

It is estimated that informal carers save the government $£ 57$ billion a year, which is the cost of providing equivalent professional care (Carers UK, 2002). Legislation and government policies implemented in 2004 and 2005 (Box 4) have improved resources for carers' support by $£ 5$ million (Department of Health,

\section{Box 4 Legislation and government policies in England and Wales with implications for carers}

1995: The Carers (Recognition and Services) Act 1995

Local authorities should provide carers with an assessment of their needs, if requested to do so, when the person that they care for is receiving an assessment of their own needs or being reassessed

1998: The Compact on Relations between Government and the Voluntary and Community Sector in England (http://www.thecompact.org.uk/)

Government code of good practice for work with the voluntary and community sector

1999: The National Strategy for Carers (Department of Health, 1999a)

Contains eight sections on the needs of carers, including a section dedicated to young carers

1999: Standard 6 of the National Service Framework for Mental Health (Department of Health, 1999b)

States the rights of carers to have their own care plan and annual assessment of needs

2000: The Carers and Disabled Children Act 2000

Gives family carers who provide regular and substantial care, the right to have an assessment of their needs, irrespective of whether or not the person being cared for is being assessed. It gives local authorities the powers to provide carers with services in their own right for the first time.

2001: The Health and Social Care Act 2001 (Section 11)

It is a requirement for strategic health authorities, primary care trusts and national health service trusts to involve and consult patients and the public about carers' issues

2002: The National Health Service Reform and Health Care Professions Act 2002

The Commission for Patient and Public Involvement in Health has the remit to set up forums for patients and carers for Independent Complaints and Advocacy Services

\section{3: The Community Care (Delayed Discharges etc.) Act 2003}

Gives carers the right to have their own assessment and to request a home visit to assess what aids and services are required before the care recipient can be discharged from hospital. It provides the opportunity to have free services (e.g. domiciliary and personal care) for 6 weeks

2004: The Carers (Equal Opportunities) Act 2004

Places a duty on local authorities to inform carers of their right to an assessment and to consider the carers' needs and wishes to combine caring with paid work, their opportunities for leisure and for life-long learning. It requires other local authority agencies to work with adult social care services to provide carers' services. There is a separate requirement for local health services to cooperate with local authorities in providing support to carers. Consequently other departments of the local authority, primary care trusts and local NHS healthcare trusts can be asked to provide services for carers and must respond to the requests

2005: The Mental Capacity Act 2005 (Due to come into force in 2007)

This amends the court of protection and power of attorney systems and sets guidelines for individuals with limited mental capacity to do as much as they can within their capability and periodically to allow others to make decisions on a limited range of issues on their behalf 
2004). The NHS Plan (Department of Health, 2000) set a national target of employing 700 carers' support workers before 2005, but this has not yet been fully implemented (Department of Health, 2004). Although people may not want to be recognised or labelled as carers, openly acknowledging their role can help them to gain access to support and services.

\section{Mental health services}

The government in England commissioned the Social Policy Research Unit, University of York to evaluate current research on the effectiveness of the interventions for carers of people with dementia or mental illness. It has also recognised that further research is needed to evaluate the benefits of carers' breaks, support, and education and training programmes (Department of Health, 2004). Engagement of carers at the first episode of illness, or as soon as possible afterwards, is considered to be beneficial in improving the long-term prospects of those involved (Goldstein et al, 1978). The British Medical Association (2003) has produced guidance on good practice for professionals working with carers.

Standard six of the National Service Framework for Mental Health (Department of Health, 1999b) relates specifically to the needs of carers, and it states that:

'All individuals who provide regular and substantial care for a person on CPA [the care programme approach] should:

- have an assessment of their caring, physical and mental health needs, repeated on at least an annual basis

- have their own written care plan which is given to them and implemented in discussion with them' (Department of Health, 1999b: p. 69).

It is implied that carers should have their own keyworkers. However, this is not always possible or acceptable. An alternative would be to refer carers to the voluntary sector for support and encouragement. The unavailability of a keyworker for a carer should not prevent that carer from having an annual carers' assessment and a written care plan (Box 5).

In mental health services, if a carer has a care plan this should be recorded in the care recipient's clinical record and, if the carer agrees, the care plan can be sent to the carer's GP.

Carers may need extra support at times of transition in their lives or when the care recipient moves to another stage of care, perhaps a hospital or long-stay facility. Many carers feel guilty and ashamed that they can no longer cope, but others are relieved that the burden of care will lessen. Carers

\section{Box 5 Example of a care plan for a carer}

Information for carer

- Obtain information on what a carer needs to be able to undertake their care duties

- Provide information on how to get help in a crisis

- Provide information on how to deal with particular situations

- Provide information on where to obtain advice on financial and social matters

Plan

- Define what is required to meet the carer's needs

- State how these needs will be met

- Record unmet need and attempts to remedy any unmet need

Support

- Provide information on where to get support from carers' groups or other organisations

- Plan and obtain respite or short breaks

- Provide information about complaints procedures

(Adapted from Carers Advisory Group, 2001)

themselves may gradually become physically or mentally ill and need advice to attend their general practitioner (GP).

Psychiatrists should be aware of carers' health and well-being and ask their patients whether they are carers and whether they need additional support. Letters to and from mental health professionals to GPs should state whether the patient is a carer of another adult or child.

\section{Primary care services}

One in ten adult patients registered with a GP will be a carer (Office for National Statistics, 2003). Their own GP is often the first health professional with whom carers will have contact. Primary care staff are in an excellent position to identify and meet the healthcare needs of carers, especially carers who support someone with a mental illness, children who are carers, carers from Black and minority ethnic groups and carers in rural areas (Hare, 2004). Various systems can be used to compile a register of carers.

Primary care staff should ask carers about their health, provide relevant information and, when appropriate, make arrangements for them to receive healthcare from a member of the practice team such as a GP, nurse or counsellor. The recently revised General Medical Services contract for GPs provides 
financial rewards for the identification of carers and for directing them to local adult social care departments. Steps should be taken to protect carers' health by preventive measures such as vaccination for influenza and screening for hypertension, depression and other illnesses.

\section{Finance}

Good financial information and advice are crucial for both carers and care recipients, to enable them to make informed decisions about future long-term care and the purchasing of other services.

A care recipient under retirement age may be entitled to claim Disability Living Allowance for care at low, medium or high levels and for mobility at low or high levels. Care recipients over retirement age can claim an Attendance Allowance at either a 'day rate' or a 'day and night' rate. The care recipient makes the claim for either allowance and the benefits are paid directly to them. These benefits are not means tested and the amount awarded varies according to the level of the disability.

If the care recipient receives one of these allowances, then the carer may be able to claim state benefits as follows. Carers' Allowance may be claimed by a carer who provides care for one person for $>35$ hours per week, provided that the care recipient receives either a Disability Living Allowance for care at medium or high levels, or an Attendance Allowance. Carers above retirement age are entitled to claim either a Carer's Allowance or a pension.

Information on UK state benefits and eligibility criteria is available from the Department of Work and Pensions (website: http://www.dwp.gov.uk), the UK government's website Directgov (http:/ / www. direct.gov.uk/Homepage) and the Department of Work and Pensions' Disability Carers' Service and Benefit Enquiry Line (tel.: 08008822 00).

Charitable and benevolent funds may have designated monies to assist certain categories of beneficiary.

\section{Legal}

Carers worry about whether they will lose their home and may not know how to manage practical issues if the care recipient loses their mental capacity. It might be appropriate for those involved to seek legal advice and consider whether it is timely for the care recipient and the carer to review their wills. The Mental Capacity Act 2005, covering England and Wales, does not come into force until 2007 (Box 4). However, the Department of Health in England has published useful guidance on consent and mental capacity issues (Department of Health, 2001a,b,c).
Healthcare professionals should consider giving the care recipient the opportunity to make an advance directive, ${ }^{1}$ which could reduce the strain on both carer and care recipient.

\section{Training for carers}

Carers may need training in practical procedures such as wound care, catheter management, and lifting and handling techniques. Carers of people with mental disorders may need training to recognise early signs of relapse and to reduce expressed emotion. The National Institute for Clinical Excellence (now the National Institute for Health and Clinical Excellence, NICE) recommends the use of behavioural family therapy to help people with schizophrenia (National Institute of Clinical Excellence, 2002). More carers are being trained in techniques to cope with challenging behaviour. In 2004, City and Guilds, a provider of vocational qualifications in the UK, launched an e-learning course on personal development and learning for unpaid carers (go to http://www. cityandguilds.com/ and follow the links for Learners, then Learning for Living).

The European Federation of Associations of Families of People with Mental Illness (EUFAMI) has developed training packages in 12 European languages for carers and care recipients, to work with professionals to improve coping and communication skills, citizenship and the relationship between care recipients, families and professionals (http:/ / www. eufami.org/prospect/en).

\section{Physical healthcare of care recipients}

Often carers are responsible for ensuring that care recipients receive adequate physical healthcare. It can be stressful and tiring for carers to attend appointments with care recipients. There may be problems with public transport, inconvenient appointment times, long waiting times and the healthcare professional may not be willing to speak to the carer. Carers often do not realise that their own GP or the care recipient's keyworker may be able to assist them.

\section{Voluntary-sector support for carers}

In the UK, several organisations in both the state and voluntary sectors support and educate carers of people with physical and mental disorders. Some

\footnotetext{
1. Advance directives have been discussed in an earlier issue of APT: see Williams, L. \& Rigby, J. (2004) Advance statements in old age psychiatry. Advances in Psychiatric Treatment, 10, 260-266. Ed.
} 


\section{Box 6 Useful sources of help and information}

Web addresses

- Age Concern

- Alzheimer's Disease International

- Alzheimer's Society

- Alzheimer Scotland - Acting on Dementia

- Carers UK - The Voice of Carers

- Crossroads - Caring for Carers

- Foundation for People with Learning Disabilities

- Caring about Carers

- Together

- Mencap

- Mental Health Alliance

- Methodist Homes for the Aged

- Mental Health Foundation

- Mind

- National Institute for Mental Health in England (NIMHE)

- Princess Royal Trust for Carers

- Youngcarers.net

- Partners in Care

- Rethink

- Sane

- YoungMinds http://www.ageconcern.org

http://www.alz.co.uk

http://www.alzheimers.org.uk

http://www.alzscot.org

http://www.carersuk.org

http://www.crossroads.org.uk

http://www.crossroads-scotland.co.uk

http://www.learningdisabilities.org.uk

http://www.carers.gov.uk

http://www.together-uk.org

http://www.mencap.org.uk

http://www.mentalhealthalliance.org.uk

http://www.mha.org.uk

http://www.mentalhealth.org.uk

http://www.mind.org.uk

http://www.nimhe.org.uk

http://www.carers.org

http://www.youngcarers.net

http://www.partnersincare.co.uk

http://www.rethink.org

http://www.sane.org.uk

http://www.youngminds.org.uk

Literature

Ramsay et al (2002) Mental Illness. A Handbook for Carers

voluntary-sector organisations (such as the Princess Royal Trust for Carers, Carers UK and Crossroads - Caring for Carers) focus primarily on lobbying for carers' rights and the provision of services for carers. The Princess Royal Trust for Carers has a network of 130 carers' centres throughout the UK. They provide local services and support to carers that are carer led and carer determined. These include information, emotional support, education, training, and opportunities for recreation and social activities. They also enable carers' views to be heard and recognised.

Other voluntary organisations focus mainly on the needs of individuals with certain conditions, on research or on providing information and support for patients, but many of these also have an interest in carers. These include organisations such as Rethink (formerly the National Schizophrenia Fellowship), the Foundation for People with Learning Disabilities and the Alzheimer's Society, which have informative websites (Box 6). Rethink has over 400 community services in England and Northern Ireland, with sister charities in Wales and Scotland. It publishes several booklets and provides services targeted at the carers of people with mental health difficulties. Healthcare professionals should have a list of contact details and information on the voluntary-sector organisations to give to carers.

\section{Partners in care}

In 2004, the Royal College of Psychiatrists and the Princess Royal Trust for Carers launched a joint campaign for carers entitled 'Partners in Care', which was designed to promote better relationships between carers and mental health professionals (http://www.partnersincare.co.uk/). Campaign leaflets intended for both audiences include three checklists of questions and useful tips on how to improve information-sharing during consultations between professionals, carers and patients.

Other leaflets inform carers of people with specific mental health problems and one, Carers and Confidentiality in Mental Health, discusses confidentiality and information-sharing. The leaflets are available from the campaign website (http://www.partnersincare.co.uk) or from dhart@ rcpsych.ac.uk. 


\section{Conclusions}

Attitudes to carers of people with mental disorders are gradually changing, but carers still have difficulty accessing and working with health professionals as 'partners in care'. The health of carers is not sufficiently addressed and is often not taken into account at all. All healthcare professionals should focus more on the healthcare needs of carers to ensure that they are able to maintain their physical and mental health while undertaking their care duties and responsibilities. This article has endeavoured to outline ways in which carers can be supported in their work.

\section{Declaration of interest}

Irene Cormac and Peter Tihanyi are members of the Partners in Care campaign of the Royal College of Psychiatrists and the Princess Royal Trust for Carers.

\section{References}

British Medical Association (2003) Working with Carers: Guidelines for Good Practice. London: BMA.

Bookwala, J., Sdaniuk, B. \& Burton, L., et al (2004) Concurrent and long-term predictors of older adults' use of community-based long-term care services: the Caregiver Health Effects Study. Journal of Aging and Health, 16, 88-115.

Carers UK (2002) Adding Value: Carers as Drivers of Social Change. London: Carers UK.

${ }^{*}$ Cassells, C., Geront, M. \& Watt, E. (2003) The impact of incontinence on older spousal caregivers. Journal of Advanced Nursing, 42 607-616.

Cheffings, J. (2003) Report of the Princess Royal Trust for Carers. London: Princess Royal Trust for Carers.

Department of Health (1999a) Caring about Carers: a National Strategy for Carers. London: Department of Health.

Department of Health (1999b) The National Service Framework for Mental Health: Modern Standards and Service Models. London: Department of Health.

Department of Health (2000) The NHS Plan: A Plan for Investment, a Plan for Reform. London: Department of Health.

Department of Health (2001a) Seeking Consent: Working with People with Learning Disabilities. London: Department of Health. http://www.doh.gov.uk/consent

Department of Health (2001b) Seeking Consent: Working with Older People. London: Department of Health. http:/ / www.doh.gov. uk/consent

Department of Health (2001c) Reference Guide to Consent for Examination or Treatment. London: Department of Health. http://www.doh.gov.uk/consent

Department of Health (2004) The National Service Framework for Mental Health - Five Years On. London: Department of Health.

Department of Health (2005) National Strategy for Carers. London: Department of Health. http://www.carers.gov.uk/pdfs/care. pdf

Evans, D. T. (2000) Speaking of sex: the need to dispel myths and overcome fears. British Journal of Nursing, 9, 650-655.

General Medical Council (2004) Confidentiality: Protecting and Providing Information. http://www.gmc-uk.org/guidance/ library/confidentiality.asp

Goldstein, M. H., Rodnick, E. H., Evans, J. R., et al (1978) Drug and family therapy in the aftercare of acute schizophrenia. Archives of General Psychiatry, 35, 1169-1177
Grant, J. S., Bartolucci, A. A., Elliot,T. R., et al (2000) Sociodemographic, physical, and psychosocial characteristics of depressed and non-depressed family caregivers of stroke survivors. Brain Injury, 14, 1089-1100.

Grasel, E. (2002) When home care ends: changes in the physical health of informal caregivers caring for dementia patients: a longitudinal study. Journal of the American Geriatrics Society, 50, 843-849.

*Hare, P. (2004) Keeping carers healthy: the role of community nurses and colleagues. British Journal of Nursing, 9, 155-159.

Hervey, N. \& Ramsay, R. (2004) Carers as partners in care. Advances in Psychiatric Treatment, 10, 81-84.

Keeley, B. \& Clarke, M. (2002) Carers Speak Out Project. Report on Findings and recommendation. London: Princess Royal Trust.

Kersten, P., McLellan, L., George, S., et al (2001) Needs of carers of severely disabled people: are they identified and met adequately? Health and Social Care in the Community, 9, 235-243.

Kiecolt-Glaser, J. K., Dura, J. R., Speicher, C. E., et al (1991) Spousal caregivers of dementia victims: longitudinal changes in immunity and health. Psychosomatic Medicine, 53, 345-361.

Kiecolt-Glaser, J. K., Glaser, R., Gravenstein, S., et al (1996) Chronic stress alters the immune response to influenza virus vaccine in older adults. Proceedings of the National Acadamy of Sciences of the United States of America, 93, 3043-3047.

Kiecolt-Glaser, J. K., Marucha, P. T., Malarky, W. B., et al (1995) Slowing of wound healing by psychological stress. Lancet, 346, 1194-1196.

King, A. C., Oka, R. K. \& Young, D. R. (1994) Ambulatory blood pressure and heart rate responses to the stress of work and caregiving in older women. Journal of Gerontology, 49, 239-245.

Knight, R. G., Williams, S., McGee, R. et al (1998) Caregiving and well-being in a sample of women in midlife. Australian and New Zealand Journal of Public Health, 22, 616-620.

Kristjanson, L. J. \& Aoun, S. (2004) Palliative care for families: remembering the hidden patients. Canadian Journal of Psychiatry, 49, 359-365.

Kurtz, M. E., Kurtz, J. C., Given, C. W., et al (2004) Depression and physical health among family caregivers of geriatric patients with cancer. Medical Science Monitor, 10, CR447-CR456.

LeBlanc, A. J., Driscoll, A. K. \& Pearlin, L. I. (2004) Religiosity and the experience of caregiver stress. Aging and Mental Health, 8, $410-421$.

Livingston, G., Manela, M. \& Katona, C. (1996) Depression and other psychiatric morbidity in carers of elderly people living at home. BMJ, 312, 153-156.

National Institute for Clinical Excellence (2002) Schizophrenia: Core Interventions in the Treatment and Management of Schizophrenia in Primary and Secondary Care. London: NICE. http:/ / www.nice. org.uk/page.aspx?o=42424

O'Connell, B., Bailey, S. \& Walker, A. (2003) Promoting the health and well-being of older carers: a proactive strategy. Australian Health Review, 26, 78-86.

Office for National Statistics (2003) Census 2001. National Report for England and Wales. London: TSO (The Stationery Office).

O’Rourke, N., Cappeliez, P. \& Guidon, S. (2003) Depressive symptoms and physical health of caregivers of persons with cognitive impairment: analysis of reciprocal effects over time. Journal of Aging Health, 15, 688-712.

Patel, A., Knapp, M., Evans, A., et al (2004) Training care-givers of stroke patients: economic evaluation. BMJ, 328, 1102.

Perlick, D. A., Rosenheck, R. A., Clarkin, J. F., et al (2004) Impact of family burden and affective response on clinical outcome among patients with bipolar disorder. Psychiatric Services, 55, 1029-1035.

Perring, C., Twigg, J. \& Atkin, K. (1992) Families caring for people diagnosed as mentally ill: the literature re-examined. Social Policy Research Unit. London: TSO (The Stationery Office).

Pinfold, V. \& Corry, P. (2003) Who cares? The Experiences of Mental Health Carers Accessing Services and Information. Kingston-Upon-Thames: Rethink.

Pinquart, M. \& Sorensen, S. (2004) Associations of caregiver stressors and uplifts with subjective well-being and depressive mood: a meta-analytic comparison. Ageing and Mental Health, $8,438-449$. 
Ramsay, R., Gerada, C., Mars, S., et al (2002) Mental Illness: A Handbook for Carers. Gateshead: Athenaeum Press.

* Royal College of Psychiatrists (2004) Carers and Confidentiality in Mental Health. Issues Involved in Information-Sharing. London: Royal College of Psychiatrists. http://www.rcpsych.ac.uk/ campaigns/pinc/Carersandconfidentiality.pdf

* Royal College of Psychiatrists (2006) Good Psychiatric Practice: Confidentiality and Information Sharing (Council Report CR133). London: Royal College of Psychiatrists. http:/ / www.rcpsych. ac.uk/publications/cr/cr133.htm

Schulz, R. \& Beach, S. R. (1999) Caregiving as a risk factor for mortality: the caregiver health effects study. Journal of American Medical Association, 282, 2215-2219.

Schulz, R. \& Matire, L. M. (2004) Family caregiving of persons with dementia: prevalence, health effects and support strategies. American Journal of Geriatric Psychiatry, 12, 240-249.

Shanks-McElroy, H. A. \& Strobino, J. (2001) Male caregivers of spouses with Alzheimer's disease: risk factors and health status. American Journal of Alzheimer's Disease and Other Dementias, 16, 167-175.

Singleton, N., Maung, N. A., Cowie, J., et al (2002) Mental Health of Carers. London: Office for National Statistics.

Sunmin Lee, S. D., Golditz, G. A., Berkman, L. F., et al (2003) Caregiving and risk of coronary heart disease in U.S. women; a prospective study. American Journal of Preventative Medicine, 24, 113-119.

Travers, A. F. (1996) Caring for older people: carers. BMJ, 313, $482-486$.

van den Heuvel, E. T. P., de Witte, L. P., Schure, L. M., et al (2001) Risk factors for burnout in caregivers of stroke patients, and possibilities for intervention. Clinical Rehabilitation, 15, 669-677.

Wong, D. F. K. (2000) Stress factors and mental health of carers with relatives suffering from schizophrenia in Hong Kong: implications for culturally sensitive practices. British Journal of Social Work, 30, 365-382.

${ }^{*}$ Denotes articles of particular interest.

\section{MCQs}

1 Carers of older people:

a have better mental health if they have at least eight people in their social network

$\mathrm{b}$ are less likely to be depressed if they are women

c are more likely to have osteoarthritis than noncarers

d consult their GP more often after the care role has ended

e have a lower risk of hypertension than non-carers.

2 Primary care services:

a should offer carers information about local carers' organisations

b must provide each carer with an annual health check carried out by a practice nurse

c must inform social services about carers' needs

$\mathrm{d}$ ensure that each carer obtains a 'fitness to care' certificate

e ask patients for permission to give information about their health to the carer.
3 The following statistics about carers have been published:

a the largest group of carers care for people with learning disabilities

$\mathrm{b}$ there are fewer than a million carers in the UK

c lifelong affection for the care recipient is detrimental to the carer's well-being

d female carers tend to be more traumatised by the caring role

e cultural beliefs do not affect carers' readiness to accept assistance.

4 As regards carers' legislation and government policies in England and Wales:

a the first Act of Parliament about carers was the Carers (Recognition and Services) Act 1995

b the Mental Capacity Act 2005 amends the power of attorney system

c the National Service Framework for Mental Health does not mention carers

d the Carers and Disabled Children Act 2000 gives carers the right to an assessment of their own needs

e the Community Care (Delayed Discharges etc.) Act 2003 makes carers responsible for paying for the care recipient's personal care for 6 weeks.

5 Care plans for carers:

a should be renewed every 6 months

b should provide information on where to obtain support from carers' groups or organisations

c need not be provided if the care recipient is under 16 years old

d can only be drawn up by a social worker

e should record unmet needs that have been identified but cannot be met.

\section{MCQ answers}

$\begin{array}{llllllll}1 & & 2 & & 3 & 4 & 5 \\ \text { a } & \text { T } & \text { a T } & \text { a T } & \text { a T } & \text { a F } \\ \text { b F } & \text { b F } & \text { b F } & \text { b T } & \text { b T } \\ \text { c F } & \text { c F } & \text { c F } & \text { c F } & \text { c F } \\ \text { d T } & \text { d F } & \text { d F } & \text { d T } & \text { d F } \\ \text { e F } & \text { e T } & \text { e F } & \text { e F } & \text { e T }\end{array}$

